\title{
Fracture Heat Map of The Facial Skull Demonstrates a Danger Zone of Concomitant Cervical Spine Injuries
}

\author{
Ákos Bicsák ( $\square$ akos.bicsak@klinikumdo.de) \\ Dortmund General Hospital, Department of Oral- and Maxillofacial Surgery, Plastic Operations \\ Robert Sarge \\ Dortmund General Hospital, Department of Neurosurgery \\ Oliver Müller \\ Dortmund General Hospital, Department of Neurosurgery \\ Stefan Hassfeld \\ Dortmund General Hospital, Department of Oral- and Maxillofacial Surgery, Plastic Operations \\ Lars Bonitz \\ Dortmund General Hospital, Department of Oral- and Maxillofacial Surgery, Plastic Operations
}

\section{Research Article}

Keywords: maxillofacial injury, cervical spine injury, fracture, initial trauma assessment

Posted Date: December 14th, 2020

DOl: https://doi.org/10.21203/rs.3.rs-124119/v1

License: @ (i) This work is licensed under a Creative Commons Attribution 4.0 International License. Read Full License 


\section{Abstract}

Concomitant maxillofacial and cervical spine injuries occur in $0.8 \%-12 \%$ of the cases. We examined the relation of injury localization and the probability of cervical spine fracture.

A retrospective study was conducted on patients that have been treated at Dortmund General Hospital for injuries both to the maxillofacial region and to the cervical spine between January $1^{\text {st }}, 2007$ and December $31^{\text {th }}$, 2017. Descriptive statistical methods were used to describe the correlation of cervical spine injuries with gender, age as well as maxillofacial injury localization.

7708 patients were hospitalized with maxillofacial injury, among them 173 were identified with cervical spine injury. The average ages for both genders lie remarkably above the average of all maxillofacial trauma patients (36.2 y.o. in male and 50.9 y.o. in female). In the group of men, most injuries were found between the ages of 50 and 65 . Whereas most injuries among women occurred after the age of 80 . The relative ratio of cervical spine injuries (CSI) varies between $1.1 \%$ and $5.26 \%$ of the maxillofacial injuries (MFI), being highest in the soft tissue injury group, patients with forehead fractures $(3.12 \%)$ and patients with panfacial fractures $(2.52 \%)$. Further, nasal, Le Fort I and II, zygomatic complex and mandibular condyle fractures are often associated with CSI. Fractures next to the Frankfurt horizontal plane represent $87.7 \%$ of all MFI with concomitant CSI.

Patients in critical age groups with a high-energy injury are more likely to suffer both, MFI and CSI injuries. Our findings help to avoid missing the diagnosis of cervical spine injury in maxillofacial trauma patients.

\section{Introduction}

Both maxillofacial injuries (MFI) and cervical spine injuries (CSI) are well-known to maxillofacial surgeons and neurosurgeon treating trauma cases. Nevertheless, only a few papers are handling concomitant MFI and CSI (MFI-CSI). The incidence of MFICSI ranges from $0.8-12 \%$ according to the recent literature ${ }^{1-6}$. However, the largest registry studies, , report an incidence of 1.1$11.3 \%^{7-10}$, single-center studies estimate the occurrence of $0.8-9.7 \%^{1-3,11}$. In lethally injured patients this incidence is reported as high as $46.4 \%{ }^{12}$.

The injuries of the maxillofacial region (MFI) in these patients include soft tissue injuries as well as complex panfacial fractures 10,13-15. The injury pattern of the cervical spine (CSI) ranges from distortion and severe bony or ligamentous injuries to injuries of the spinal cord itself. ${ }^{11,15-19}$. An inadequate or delayed diagnosis can have disastrous consequences and may even lead to the death of the patient. It seems that fatal cases are more common in combined MFI-CSI ${ }^{12}$. Still, CSI is often misdiagnosed even though the awareness of a thoroughly examination of the patients should be in routine practice of every trauma center ${ }^{18,20-23}$. Since severe cervical spine injuries can also be asymptomatic, it is important to perform an emergency radiologic assessment, for this purpose according to the ATLS guidelines 9,18,20,21,23-25. A proper initial assessment of the patient at the accident site and in the emergency room allows the initiation of adequate therapy, and if required, surgical therapy for both MFI and CSI to decrease overall complications $5,21,25$.

Thorough knowledge of the relation of facial injuries and cervical spine injuries helps with initial patient assessment even in stressful situations and can avoid delayed or missed diagnosis with potentially catastrophic consequences. This study aims to analyze the data from the Dortmund Maxillofacial Trauma Registry from the years 2007 to 2017 and to compare these data with the international literature. The most important research question of the study is which patients are mostly endangered to suffer $\mathrm{MFI-CSI}$ and whether there is a specific fracture site localization of the maxillofacial region that predisposes to cervical spine injuries?

\section{Methods}

The Ethics Committee of the University of Witten-Herdecke granted a written exemption for this retrospective study (152/2017). 
We conducted a retrospective analysis of the patient data accessed in the hospital electronic repository. The analysis was carried out by selecting the appropriate patients using the codes of the disease-related groups (DRG). All patient records that have been treated at our hospital for injuries both to the head and neck region and to the cervical spine between 1st of January and 31th of December. 2017 were analyzed for study purposes. The fracture sites of the facial skull were analyzed by an experienced maxillofacial surgeon. Soft tissue injury data was collected based on the electronic document repository. The injuries to the cervical spine were analyzed by an experienced neurosurgeon. The demographic data regarding the population of the City of Dortmund have been acquired from the official demographic record published by the City Council Department. The statistical analysis was performed using descriptive statistical methods with Microsoft Excel 2013 (®Microsoft Corp., Redmond, US). The epidemiological data were standardized based on the general demographic data (age and gender distribution) presented by the Authorities of the City of Dortmund ${ }^{26}$. The analysis of statistical significance was performed with standard chi-square $\left(\chi^{2}\right)$-test.

\section{Results}

In the study period from January 2007 to December 2017 a total of 7008 patients have been treated with maxillofacial injuries (Table 1). Among them, 4790 were male and 2218 female. A total of 173 patients had CSI, among them 106 male and 67 females. The gender difference is both in the total study population and in patients with CSI significant ( $\chi^{2}$ - test). The minimum age was 3.2 years, the oldest patient was 95 years old, both female. In the male the youngest patient was 3.5 y.o., the oldest one was 93.3 y.o.

Table 1

Demographics of the study population. * refers to age data in the patient group with concomitant CSI. P-values represent the $p$-values of $\chi^{2}$-test analyzing the difference between the two genders (confidence interval: $p=$

\begin{tabular}{|lllll|}
\hline & Male & Female & Total & p-value \\
\hline Total number of patients with MFI & 4790 & 2218 & 7008 & $<0.001$ \\
\hline Patients with CSI & 106 & 67 & 173 & $<0.001$ \\
\hline Mean age* & 49.2 & 55.8 & 52.3 & - \\
\hline Minimum age* $^{*}$ & 3.5 & 3.2 & 3.2 & - \\
\hline Maximum age $^{*}$ & 93.3 & 95 & 95 & - \\
\hline
\end{tabular}

Figure 1 shows the raw age-related distribution of MFI-CSI patients. The statistical analysis was based on the official demographic report of the City of Dortmund ${ }^{26}$. In the group of men, most injuries were found between the ages of 50 and 65 , while females have the highest risk above 80 years of age. The standardized histogram (Fig. 2) and the average age of injured (male 49.2 y.o., female 55.8 y.o.) in Table 1. confirm these high-risk ages. The average ages for both genders lie remarkably above the average ages of all patients with MFI in our registry (36.2 y.o. in male and 50.9 y.o. in female). Due to this significant difference between both genders, a standardization of the age-related data was performed to reduce bias originating from the differently sized groups. The difference in males is higher than in the female. After standardization of the data (Fig. 1) is this effect clearly visible (Fig. 2). Male patients have a peak of risk at the age of 50-65 y.o., their risk decreases in the highest age groups. Figure 3 shows the age-related incidence of CSI in MFI patients and in relation to the city population. The odds ratio of acquiring a CSI in an MFI patient is presented in Fig. 4. The analysis of this diagram also confirms the higher risk of females in older age.

Table 2 shows the distribution of patients based on the MFI levels and the rate of CSI in each patient group. This grouping includes all types of injuries. The difference in each group is statistically significant $\left(\chi^{2}\right.$-test, confidence interval: $\left.p<0.05\right)$, except for the soft tissue injuries, where a trend is to be seen. The relative ratio of CSI varies between $1.1 \%$ and $5.26 \%$ and is high in the soft tissue injury group, in correlation with the injuries of the upper face and in patients with panfacial fractures. 
Table 2

Patient distribution with different MFI with reference to the absolute numbers and ratio of CSI in each group. Significant $\mathrm{p}$-values are typed in bold $\left(\chi^{2}\right.$-test, confidence interval: $p<0.05)$. P-values represent the $p$-values of $\chi^{2}$-test analyzing the difference between the two groups (confidence interval: $p=0.05$ ).

\begin{tabular}{|llllll|}
\hline & CSI not detected & CSI present & Total & $\%$-CSI & p-value \\
\hline Soft tissue only & 1441 & 80 & 1521 & $5.26 \%$ & 0.162 \\
\hline Upper face & 404 & 13 & 417 & $3.12 \%$ & $<0.001$ \\
\hline Central midface & 1477 & 27 & 1504 & $1.80 \%$ & $<0.001$ \\
\hline Lateral midface & 1348 & 15 & 1363 & $1.10 \%$ & $<0.001$ \\
\hline Mandible & 1077 & 12 & 1089 & $1.10 \%$ & $<0.001$ \\
\hline Panfacial fracture & 888 & 23 & 911 & $2.52 \%$ & $<0.001$ \\
\hline Dentoalveolar only & 191 & 3 & 194 & $1.55 \%$ & $<0.001$ \\
\hline
\end{tabular}

Table 3 presents the relation of the MFI and different CSI diagnoses. On average, $2.47 \%$ of all patients with MFI presented with CSI. Most injuries to the CS are distorsions (139, 80\% of all CSI). Fractures were identified in 20 cases (11.6\% of all CSI) and traumatic stenosis of the spinal canal was diagnosed in 7 cases ( $4 \%$ of all CSI).

Table 3

The relation between the level of MFI and the detailed CSI diagnosis. (CS = cervical spine). The numbers represent absolute values.

\begin{tabular}{|c|c|c|c|c|c|c|c|c|c|}
\hline MFI level & $\begin{array}{l}\text { Total } \\
\text { number } \\
\text { of } \\
\text { patients }\end{array}$ & $\begin{array}{l}\text { Distorsion } \\
\text { of the CS }\end{array}$ & $\begin{array}{l}\text { Fracture } \\
\text { CS }\end{array}$ & $\begin{array}{l}\text { CS } \\
\text { ligament } \\
\text { rupture }\end{array}$ & $\begin{array}{l}\text { Traumatic } \\
\text { stenosis } \\
\text { of the } \\
\text { spinal } \\
\text { canal }\end{array}$ & Hematoma & $\begin{array}{l}\text { Stenosis } \\
\text { of the } \\
\text { vertebral } \\
\text { canal }\end{array}$ & $\begin{array}{l}\text { Dura } \\
\text { injury }\end{array}$ & $\begin{array}{l}\text { Contusion } \\
\text { of the } \\
\text { spinal } \\
\text { cord }\end{array}$ \\
\hline Soft tissue & 80 & 78 & 1 & 0 & 1 & 0 & 0 & 0 & 0 \\
\hline Forehead & 13 & 7 & 4 & 1 & 1 & 0 & 0 & 0 & 0 \\
\hline $\begin{array}{l}\text { Central } \\
\text { midface }\end{array}$ & 27 & 22 & 5 & 0 & 0 & 1 & 0 & 1 & 0 \\
\hline $\begin{array}{l}\text { Lateral } \\
\text { midface }\end{array}$ & 15 & 11 & 2 & 1 & 1 & 0 & 0 & 0 & 0 \\
\hline Mandible & 12 & 7 & 2 & 1 & 2 & 0 & 0 & 0 & 0 \\
\hline Polytrauma & 23 & 11 & 6 & 0 & 2 & 0 & 2 & 0 & 2 \\
\hline $\begin{array}{l}\text { Dentoalveolar } \\
\text { injuries }\end{array}$ & 3 & 3 & 0 & 0 & 0 & 0 & 0 & 0 & 0 \\
\hline Total & 173 & 139 & 20 & 3 & 7 & 1 & 2 & 1 & 2 \\
\hline
\end{tabular}

In Fig. 5 we present the visualization of the most common fracture sites in the facial skull that are associated with CSI. These are located near to the midline, like the (central) forehead, nose and LeFort I and II level or in the lateral area of the face (zygomatic bone, orbital floor or mandibular condyle). In comparison, the injuries of the mandibular angle or front, the dentoalveolar or nasoethmoidal complex represent a lower risk of CSI. This heat map provides a good visualization that fractures of the facial skull near to the Frankfurt-horizontal plane are mostly connected with CSI. In this zone, we observed $87.7 \%$ of all fractures (128 of 146). This difference is statistically highly significant $\left(p<0.00001, \chi^{2}\right.$-test, confidence interval: $\left.p<0.05\right)$.

\section{Discussion}

The initial assessment of patients in the emergency room is essential to detect life-threatening injuries or injuries that can lead to permanent disabilities ${ }^{20-22,25}$. Most maxillofacial injuries can easily be diagnosed, as the symptoms are relatively easy to 
assess. Nevertheless, severe injuries of the cervical spine can occur without alarming signs. Especially in unconscious patients, a possible injury to the cervical spine must always be considered both at the scene of the accident and in the emergency room.

Many authors point out that injuries of the CS are often misdiagnosed ${ }^{16,23}$.

The highest incidence of concomitant MSI-CSI was detected in older patients than center average of maxillofacial trauma patients. In our study, $2.47 \%$ of all MFI patients were diagnosed with a concomitant CSI. This is comparable with the literature but is lower than the international average $\left(0.8 \%^{3}\right.$ to $\left.12 \%^{5}\right)$. This result is less than reported from the German registry study by Pietzka et al. (11.3\%) or single-center studies from the UK or USA ${ }^{1,2,11}$, but more than $0.8 \%$ reported by Roccia et al from Italy ${ }^{3}$. All these studies analyze a similarly long period of time, Färkkilä et al. from the same years ${ }^{1,2}$.

Our study presents a clear demographic trend. In female patients with MFI, there is an increasing risk with increasing age to suffer a concomitant CSI.

We found that injuries located near to the cranial base (most common fracture sites were the forehead, nose, LeFort I and II level, zygomatic bone, orbital floor or mandibular condyle) both in central and in lateral areas of the facial skull are significantly more often presented with CSI than other areas of the face ( $87.7 \%$ of cases with CSI). This level represents approximately the plane of the Frankfurt horizontal. Fractures in this area may point to a far more dangerous injury of the spine, thus from our data we suggest this region can be referred to as the "Cervical Spine Injury Alert Bend" of the face. To us, it is an important finding that soft tissue injuries of the face even without jaw fractures are associated with CSI as high as $5.25 \%$ range of all soft tissue injuries $(p=0.162)$. The soft tissue injury sites were often less precisely documented; thus, a mapping was not possible. Based on the findings in the fracture group, we suppose that the same distribution will apply for patients that suffered soft tissue injuries only. In contradiction to our study, Färkkilä et al. report in total higher MFI-CSI rates in patients with mandibular fractures than in those with midface fractures ${ }^{1,2}$. After a detailed analysis of these papers, a higher incidence of CSI is reported in more cranial fractures of the lower jaw, like fractures of the mandibular collum². Their analysis of concomitant midfacial fractures and CSI provided a very similar result ${ }^{1}$ than our study.

The above findings provide important guidance for the initial assessment in the emergency room, too. We suggest considering a high-resolution CT-scan of both the cervical spine (C1-C7) and the complete facial skeleton, if

1. there is an injury in the above-described zone, and

2. the patient is a male 35-65 years old or a female above 60 years of age, and

3. the injury mechanism suggests a middle to the high-energy impact of the head with fronto-posterior hyperextension of cervical spine ${ }^{12}$ or high shear forces in the lateral midface.

These clinical findings reflect the statements of Tuchtan et al. resulting from the finite element analysis of the projection of von Mises-forces after facial blunt trauma ${ }^{27}$. This paper reports that high antero-posterior forces can result in injuries to the ligaments, blood vessels, spinal cord or brain stem. Živković et al. report the same injuries in autopsy reports ${ }^{12}$. To the best of our knowledge, this is the first report that correlates MFI to CSI based on a large clinical data analysis. Our findings correlate to both virtual modeling and postmortem studies.

From our data, we strongly suggest that a thorough patient examination should be conducted by both, experienced maxillofacial surgeons and neurosurgeons, in critically injured patients presenting with the "Facial Alert Band" (FAB). This may help to avoid diagnostic failures or delayed diagnosis, especially in unconscious patients ${ }^{23}$.

In conclusion, injuries to the cervical spine in patients with maxillofacial injuries can be life-threatening or can cause severe lifelong disability. The findings and the heat map presented in this paper can be a useful clinical tool even for an experienced team. It can reduce missing or delayed diagnosis of CSI, thus it helping to reduce possible complications, improve treatment outcome and quality and avoid legal consequences.

\section{Declarations}


Author contribution statement

The authors were responsible for the following study procedures:

\begin{tabular}{|llllllll|}
\hline & $\begin{array}{l}\text { Study } \\
\text { planning }\end{array}$ & $\begin{array}{l}\text { Ethics } \\
\text { commission }\end{array}$ & $\begin{array}{l}\text { Data } \\
\text { collection }\end{array}$ & $\begin{array}{l}\text { Data management } \\
\text { and analysis }\end{array}$ & Writing & $\begin{array}{l}\text { Text check } \\
\text { and } \\
\text { supervision }\end{array}$ & $\begin{array}{l}\text { Journal submission } \\
\text { \& correspondce }\end{array}$ \\
\hline $\begin{array}{l}\text { Ákos } \\
\text { Bicsák }\end{array}$ & $\mathrm{x}$ & $\mathrm{x}$ & $\mathrm{x}$ & $\mathrm{x}$ & $\mathrm{x}$ & & $\mathrm{x}$ \\
\hline $\begin{array}{l}\text { Robert } \\
\text { Sarge }\end{array}$ & $\mathrm{x}$ & & $\mathrm{x}$ & $\mathrm{x}$ & $\mathrm{x}$ & & \\
\hline $\begin{array}{l}\text { Oliver } \\
\text { Müller }\end{array}$ & $\mathrm{x}$ & & & & $\mathrm{x}$ & \\
\hline $\begin{array}{l}\text { Stefan } \\
\text { Hassfeld }\end{array}$ & $\mathrm{x}$ & $\mathrm{x}$ & $\mathrm{x}$ & $\mathrm{x}$ & $\mathrm{x}$ & & \\
\hline $\begin{array}{l}\text { Lars } \\
\text { Bonitz }\end{array}$ & $\mathrm{x}$ & $\mathrm{x}$ & & $\mathrm{x}$ & & \\
\hline
\end{tabular}

Acknowledgments

We thank you for the kind support of Medartis AG (Research Department and Management), especially Mrs. Dr. Annika Cattin PhD., Mr. Dr. Adrian Spiegel PhD. for their contributions.

We would like to thank Mr. Alexander Rost and Mr. Frank Niemeier at the Dortmund Clinic for providing the digital data.

\section{Funding}

The conduct of the study was scientifically supported and partially financed (ethic committee fee, statistical work and preparations for publication) by Medartis ${ }^{\circledR}$ Research (Medartis AG, Hochbergerstrasse 60E, CH-4057 Basel, Switzerland).

\section{Competing interest}

The conduct of the study was scientifically supported and partially financed (ethic committee fee, statistical work and preparations for publication) by Medartis ${ }^{\circledR}$ Research (Medartis AG, Hochbergerstrasse 60E, CH-4057 Basel, Switzerland).

Professor Dr. Dr. Stefan Hassfeld and Dr. Dr. Lars Bonitz are design surgeons at Medartis.

Ákos Bicsák, Rober Sarge and Oliver Müller declare no further financial or other conflicts of interest.

\section{Ethics committee approval, legal information}

The Ethics Commission of the University of Witten - Herdecke has approved this study (No. 152/2017).

The study was conducted in concordance with the Helsinki Declaration, ICH-GCP, laws and regulations of the European Union, those of the Federal Republic of Germany and of the State North-Rhine-Westphalia and with the internal regulations of Dortmund General Hospital.

All included patients have signed an informed consent form.

\section{References}

1. Färkkilä, E. M. et al. Frequency of cervical spine injuries in patients with midface fractures. International Journal of Oral and Maxillofacial Surgery 49, 75-81 (2020). 
2. Färkkilä, E. M. et al. Risk Factors for Cervical Spine Injury in Patients With Mandibular Fractures. Journal of Oral and Maxillofacial Surgery 77, 109-117 (2019).

3. Roccia, F., Cassarino, E., Boccaletti, R. \& Stura, G. Cervical Spine Fractures Associated With Maxillofacial Trauma: An 11-Year Review. Journal of Craniofacial Surgery 18, 1259-1263 (2007).

4. Mithani, S. K. et al. Predictable Patterns of Intracranial and Cervical Spine Injury in Craniomaxillofacial Trauma: Analysis of 4786 Patients: Plastic and Reconstructive Surgery 123, 1293-1301 (2009).

5. Lalezari, S. et al. Age and Number of Surgeries Increase Risk for Complications in Polytrauma Patients with Operative Maxillofacial Fractures. wjps 7, 307-313 (2018).

6. Elahi, M. M. et al. Cervical Spine Injury in Association with Craniomaxillofacial Fractures: Plastic and Reconstructive Surgery 121, 201-208 (2008).

7. Pietzka, S. et al. Maxillofacial injuries in severely injured patients after road traffic accidents-a retrospective evaluation of the TraumaRegister DGUß 1993-2014. Clin Oral Invest 24, 503-513 (2020).

8. Owusu, J. A., Bellile, E., Moyer, J. S. \& Sidman, J. D. Patterns of Pediatric Mandible Fractures in the United States. JAMA Facial Plast Surg 18, 1-5 (2016).

9. Mundinger, G. S. et al. Analysis of Radiographically Confirmed Blunt-Mechanism Facial Fractures: Journal of Craniofacial Surgery 25, 321-327 (2014).

10. Chu, M. W. et al. C-spine injury and mandibular fractures: lifesaver broken in two spots. Journal of Surgical Research 206, 386-390 (2016).

11. Mukherjee, S., Abhinav, K. \& Revington, P. A review of cervical spine injury associated with maxillofacial trauma at a UK

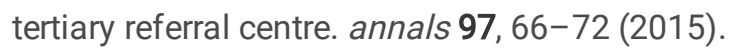

12. Živković, V. et al. Pontomedullary lacerations and concomitant head and neck injuries: their underlying mechanism. A prospective autopsy study. Forensic Sci Med Pathol 8, 237-242 (2012).

13. Beirne, J. C. Cervical spine injury in maxillofacial trauma. Br J Oral Maxillofac Surg 37, 245 (1999).

14. Choonthar, M. M. Head Injury- A Maxillofacial Surgeon's Perspective. JCDR (2016) doi:10.7860/JCDR/2016/16112.7122.

15. Haug, R. H., Wible, R. T., Likavec, M. J. \& Conforti, P. J. Cervical spine fractures and maxillofacial trauma. Journal of Oral and Maxillofacial Surgery 49, 725-729 (1991).

16. Goodenough, C. J. et al. Cervical Spine Injuries in Pediatric Maxillofacial Trauma: An Under-Recognized Problem. Journal of Craniofacial Surgery 31, 775-777 (2020).

17. Halsey, J. N. et al. Characteristics of Cervical Spine Injury in Pediatric Patients With Facial Fractures: Journal of Craniofacial Surgery 27, 109-111 (2016).

18. Kanwar, R., Delasobera, B. E., Hudson, K. \& Frohna, W. Emergency Department Evaluation and Treatment of Cervical Spine Injuries. Emergency Medicine Clinics of North America 33, 241-282 (2015).

19. Mourouzis, C., Schoinohoriti, O., Krasadakis, C. \& Rallis, G. Cervical spine fractures associated with maxillofacial trauma: A 3year-long study in the Greek population. Journal of Cranio-Maxillofacial Surgery 46, 1712-1718 (2018).

20. Langner, S., Fleck, S., Kirsch, M., Petrik, M. \& Hosten, N. Whole-Body CT Trauma Imaging with Adapted and Optimized CT Angiography of the Craniocervical Vessels: Do We Need an Extra Screening Examination? AJNR Am J Neuroradiol 29, 19021907 (2008).

21. Ngatchou, W. et al. Application of the Canadian C-Spine rule and nexus low criteria and results of cervical spine radiography in emergency condition. Pan Afr Med J 30, (2018).

22. Jesin, M. et al. Predictors of mortality, hospital utilization, and the role of race in outcomes in head and neck trauma. Oral Surgery, Oral Medicine, Oral Pathology and Oral Radiology 121, 12-16 (2016).

23. Reich, W., Surov, A. \& Eckert, A. W. Maxillofacial trauma - Underestimation of cervical spine injury. Journal of CranioMaxillofacial Surgery 44, 1469-1478 (2016).

24. Kedarnath, N. C Spine Fracture on OPG. JCDR (2013) doi:10.7860/JCDR/2013/5960.3288. 
25. Paramaswamy, R. Airway management in a displaced comminuted fracture of the mandible and atlas with a vertebral artery injury: A case report. J Dent Anesth Pain Med 18, 183 (2018).

26. Yearly report of the City of Dortmund. (2018).

27. Tuchtan, L. et al. Study of cerebrospinal injuries by force transmission secondary to mandibular impacts using a finite element model. Forensic Science International 307, 110118 (2020).

\section{Figures}

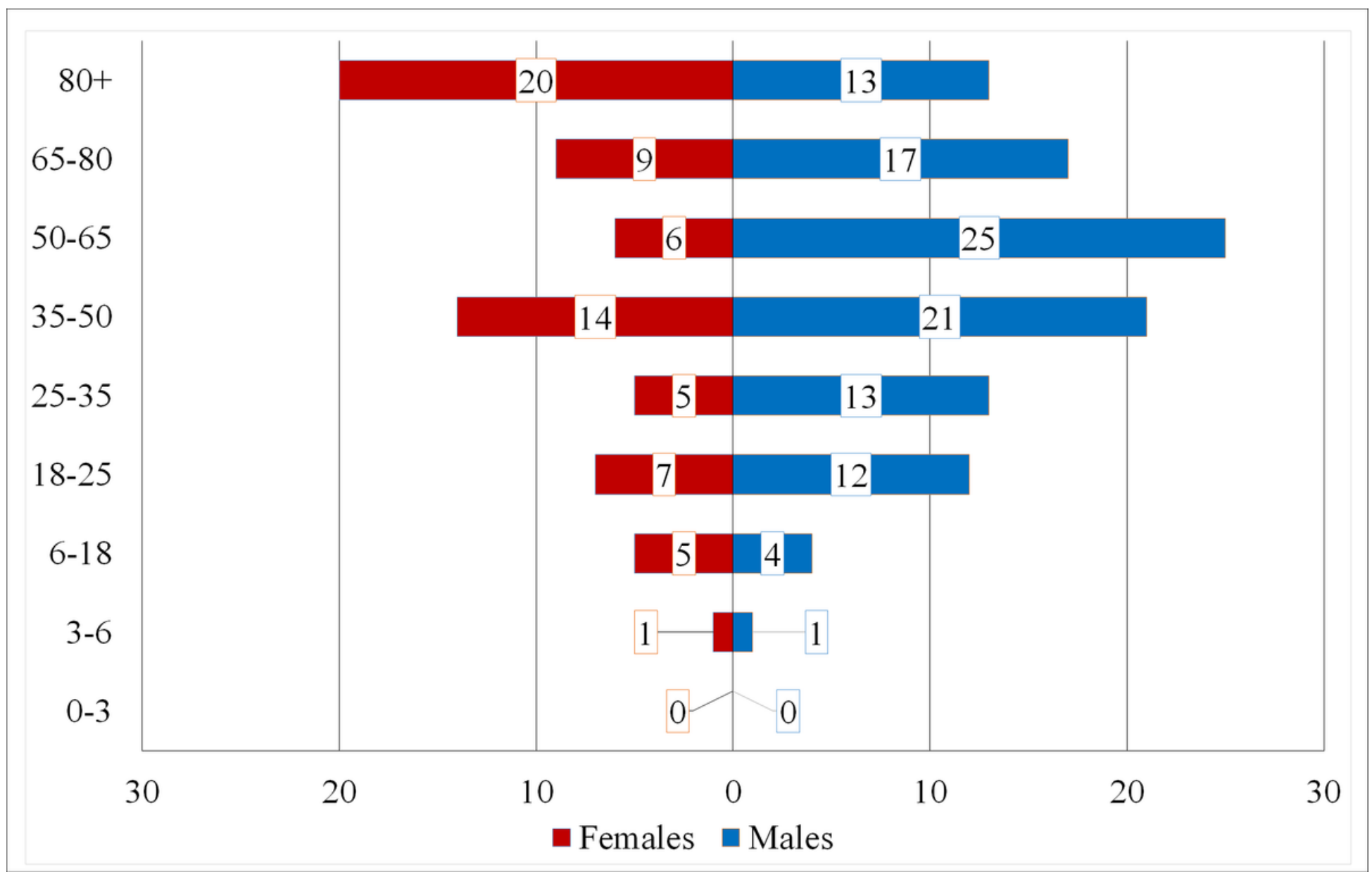

\section{Figure 1}

Histogram of the demographics of patients with concomitant CSI and MSI. 


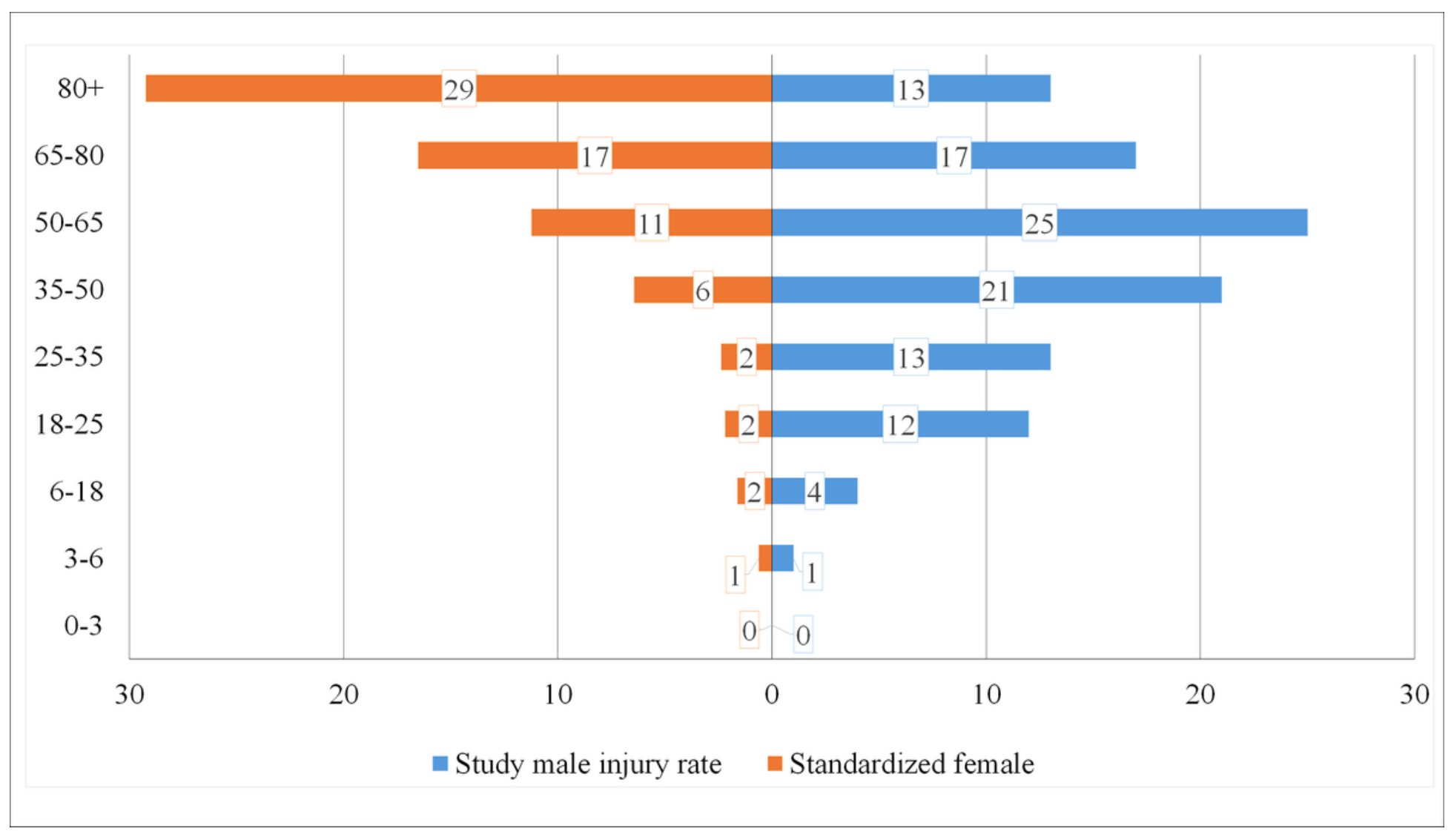

Figure 2

Standardized histogram based on the population registry report released by the Authority of the City of Dortmund of the patients with concomitant CSI and MSI. The age grouping in Figures 1 and 2 is based on the official demographic registry report for comparability. 


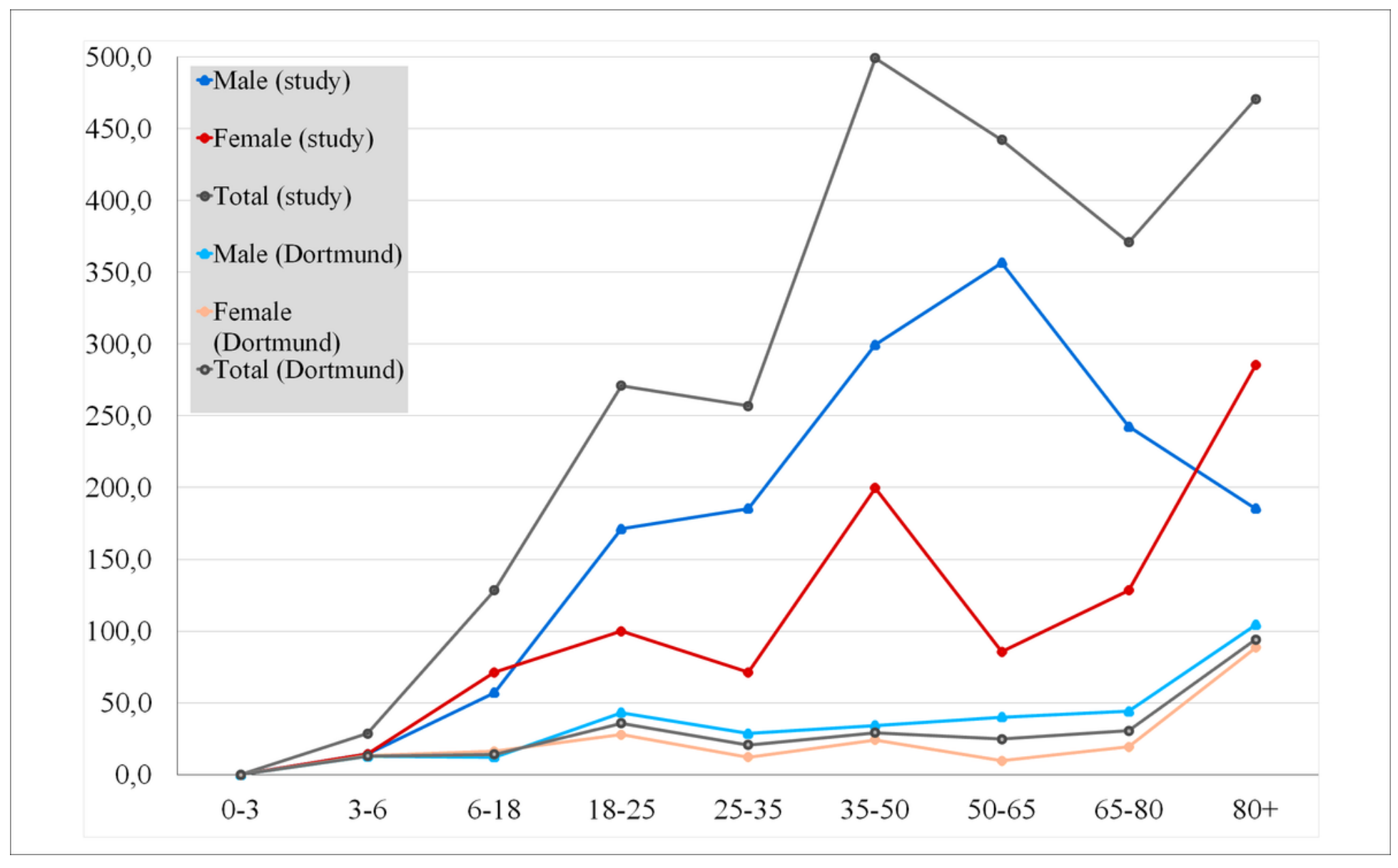

\section{Figure 3}

The incidence of CSI in the study population and MFI-CSI incidence in the whole population of Dortmund (1/100.000 inhabitants). 


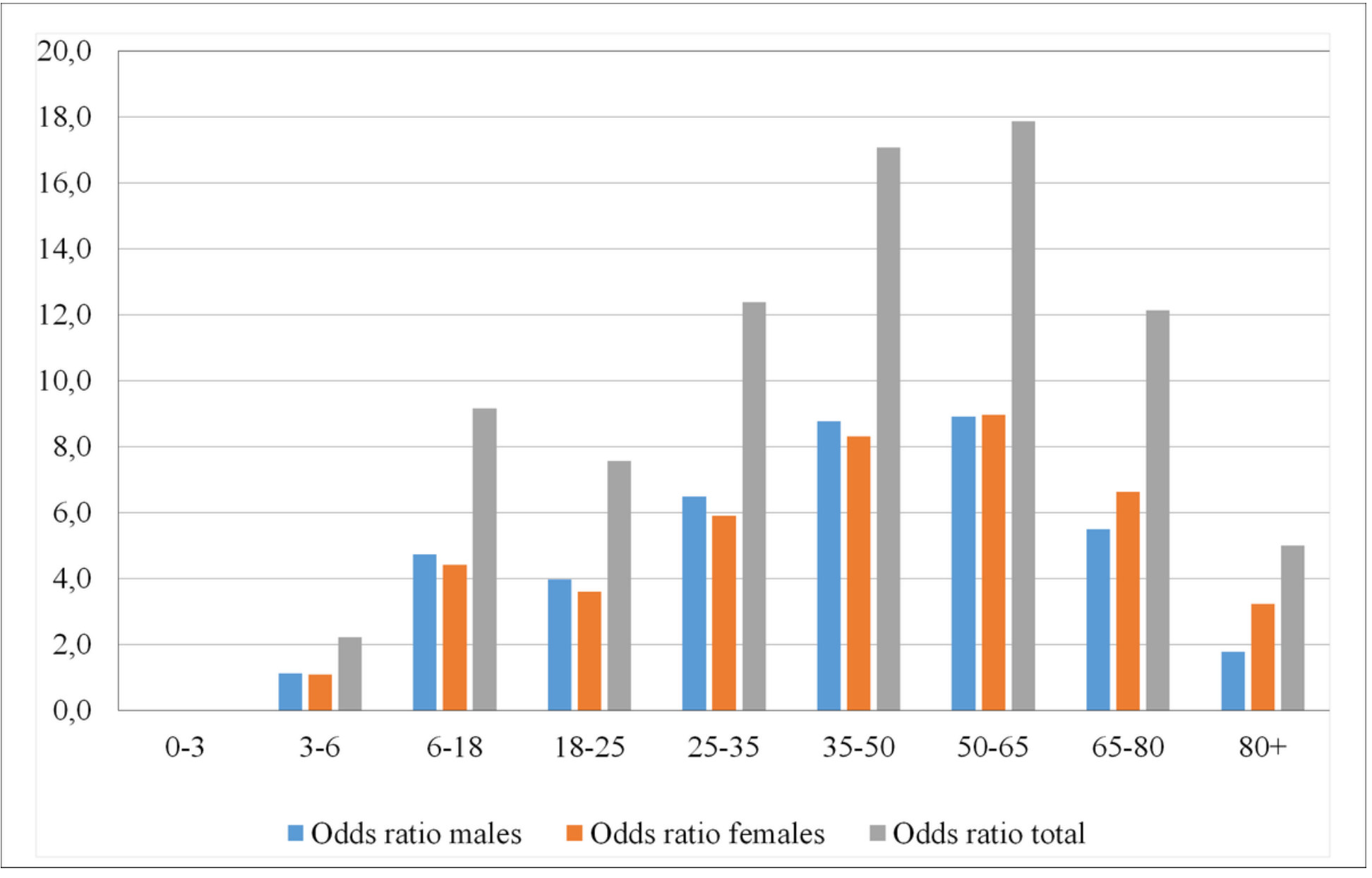

Figure 4

Presentation of the odds ratio in different gender and age groups.

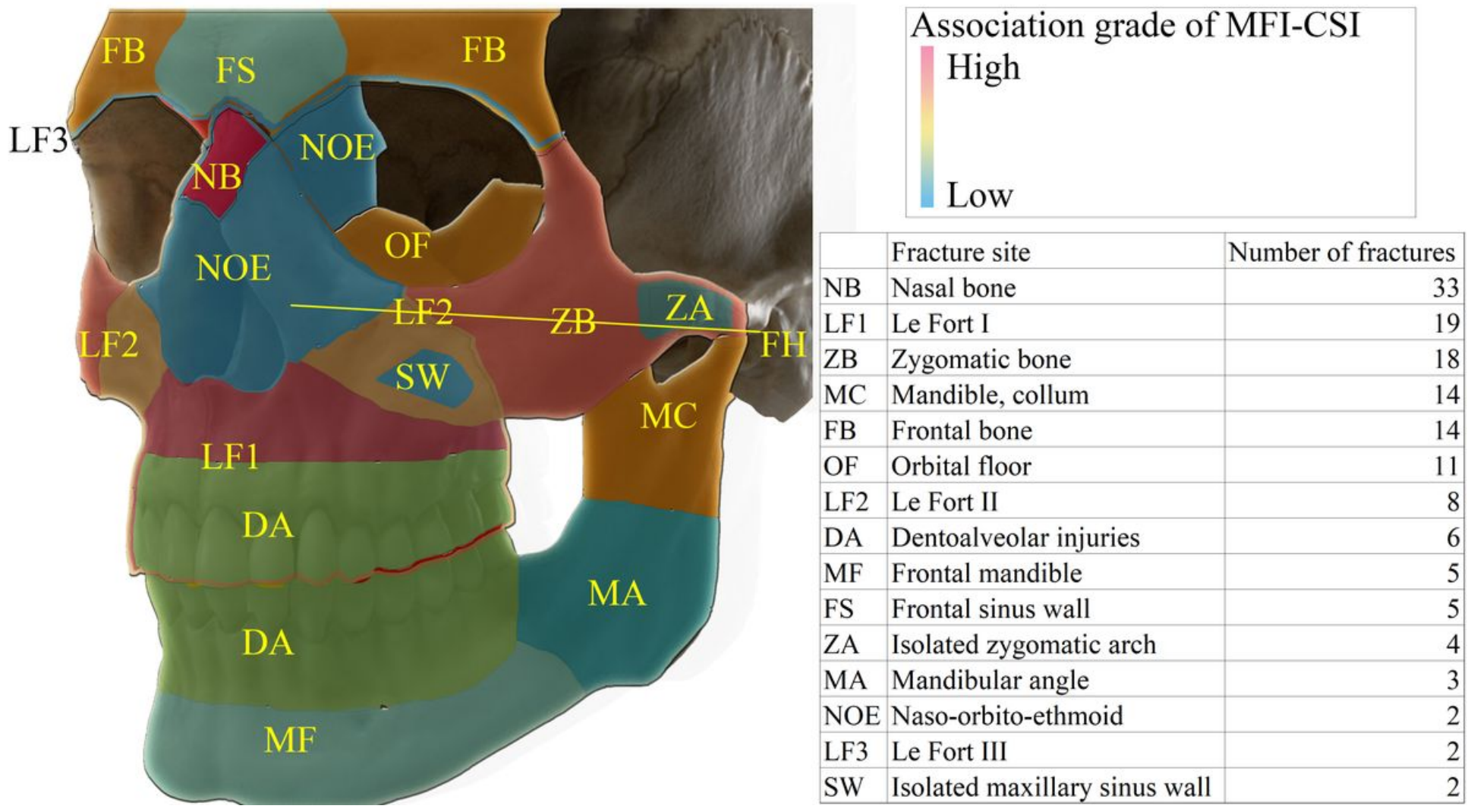




\section{Figure 5}

Heat map showing the areas of the skull with a higher risk of CSI. Fractures of the forehead, the nose, Le Fort I and II-level, zygomatic complex and the mandibular condyle are more often associated with CSI. The table includes the total number of fracture sites in MFI-CSI patients and thus does not refer to the number of patients. The yellow line represents the Frankfurt horizontal line on the left side. 